\title{
Comparison of the Reaction Time Period of Individuals in Sport, Fine Arts and
} Classroom Education

\section{H. Bayram TEMUR ${ }^{1}$ Rezan BAYTAR ${ }^{2}$}

'Assistant Professor, Physical Education and Sports High School, Yüzüncü Yıl University, Van, Turkey. Email:temurbay@hotmail.com

'Physical Education and Sports Teacher, Ministry of Education, Batman, Turkey.

Email: rezkaraca@hotmail.com

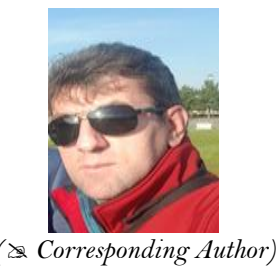

\section{Abstract}

In this study, it was aimed to compare the reaction times of individuals who are generally trained as sports teachers, fine arts teachers and class teachers, and in particular the reaction times of individuals according to the branches they receive education. For this purpose, 132 individuals from different branches and classroom teachers at the School of Physical Education and Sports and Faculty of Fine Arts were included in the study. Reaction time measurements were performed with NEWTEST 1000 instrument. Data analysis One-way Anova and Independent t test and Descriptives program were used in SPSS program. As a result of the analysis, it was found that the visual and auditory mixed reaction times of both hands were different between the groups at $\mathrm{p}$ $<0.01$. It was found that there was a difference in right hand mixed reaction time between groups at $\mathrm{p}<0.05$ level. In addition, it was found that there was a difference between right hand visual and right and left hand mixed reaction time values at the level of $\mathrm{p}<0.01$ between those who had badminton training and those who had picture training. It was determined that left hand visual and right hand auditory reaction time values were significantly shorter $(p<0.01)$ in football training subjects when compared to those who had picture training. As a result, it can be said that being a sports instructor positively affects visual, auditory and mixed reaction time and also the branches involved in the study affect the reaction time at different levels.

Keywords: Reaction time, Sedentary, Painting, Music, Football, Badminton, Volleyball, Handball, Basketball.

Citation | H. Bayram TEMUR; Rezan BAYTAR (2019) Comparison of the Reaction Time Period of Individuals in Sport, Fine Arts and Classroom Education. Asian Journal of Education and Training, 5(3): 495-500.

History:

Received: 1 July 2019

Revised: 7 August 2019

Accepted: 18 September 2019

Published: 16 October 2019

Licensed: This work is licensed under a Creative Commons

Attribution 3.0 License $(\mathrm{oc})$ )

Publisher: Asian Online Journal Publishing Group
Acknowledgement: Both authors contributed to the conception and design of the study.

Funding: This study received no specific financial support

Competing Interests: The authors declare that they have no conflict of interests.

Transparency: The authors confirm that the manuscript is an honest, Transparency: The authors confirm that the manuscript is an honest,
accurate, and transparent account of the study was reported; that no vital accurate, and transparent account of the study was reported; that no vital
features of the study have been omitted; and that any discrepancies from the study as planned have been explained.

Ethical: This study follows all ethical practices during writing.

\section{Contents}

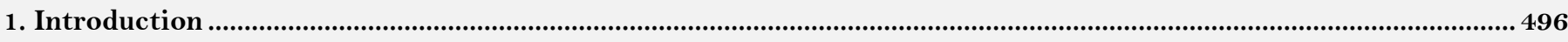

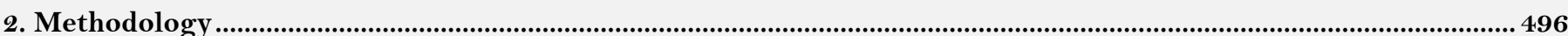

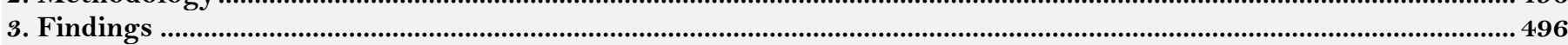

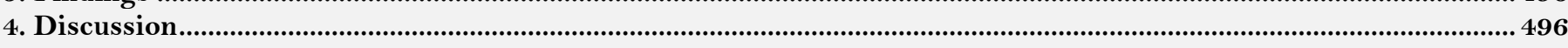

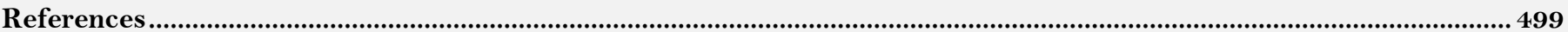




\section{Contribution of this paper to the literature}

Different studies have been done on this subject before. However, there are almost no studies comparing the reaction times of individuals who paint or play any instrument, who deal with different branches of sport and who receive more training in writing. This study is thought to be a stepping stone for further studies.

\section{Introduction}

Reaction time occurs in many areas of daily life. One of our features is necessary for the continuation of life. The fact that reaction time is short in many occupations from driving to traffic in daily life to kitchen works, healthcare, disaster management plays an important role in preventing many accidents and even saving lives. In addition, reaction time is one of the factors affecting the performance of athletes in competitions.

According to Schmidt et al. (1991) the reaction time is " interval from the start of the response to the unexpected stimulus ". According to Bompa (1998) it is the first muscular reaction or an inherited trait that determines the time between the realization of movement.

Visual reaction: The reaction time is between $0.15-0.20$ seconds.

Auditory reaction: The reaction time is between $0.12-0.27$ seconds.

Tactile reaction: The reaction time is between 0.09 - 0.18 seconds (Sevim, 1997).

In this context, Reaction time is a factor in determining the outcome of the various sports and it can be shortened by physical exercise (Çolakoğlu et al., 1993).

Reaction time incorporates a number of elements in most sport branches. Since athletes are required to respond to various stimuli in different environments, reaction time is one of the determinants of a successful performance and the athletes with the same condition and technical capacities who have shorter reaction times and are more successful. Therefore, its importance varies from sport branch to sport branch. In terms of our perceptions, particularly in terms of stimuli, the shortness of reaction time is also important in enabling us to act before our competitors in sports. For instance, badminton, table tennis, athletics are sport braches in which it is more important. In order to win in sports, the athlete must demonstrate a high level of skill in terms of physiological and motoric properties. One of the variables that can accomplish this is reaction time. The athletes with high performance will have better reaction time. Sometimes the concentration of the athletes in the competition / competition is of great importance given that one or two points difference or one or two split-second championship is achieved or not (Fox et al., 1999).

In this study, it was aimed to compare the reaction times of the individuals who were trained as sports teachers in Van Yüzüncü Yll University School of Physical Education and Sports, fine arts teachers in the Faculty of Fine Arts and classroom teachers in Faculty of Education.

\section{Methodology}

In the study, participants aged between 18 and 27 years were included on a voluntary basis. The sample of the study is consisted of 51 women and 81 men students, a total of 132, from Van Yüzüncü Yll University School of Physical Education and Sports and Faculty of Fine Arts and Faculty of Education. Eighty two of these individuals receive sports education in different branches (Volleyball: 16, Football: 18, Badminton: 11, Handball: 17, Basketball: 20) in the School of Physical Education and Sports. Thirty two of them are educated in music teaching $(\mathrm{N}$ : 18) and painting teaching (N: 16) departments of Faculty of Fine Arts. Sixteen students having sedentary lifestyle were randomly chosen from the Department of Primary School Teaching. In this selection, the participants who had no chronic disease, not using a continuous medication, not having sedentary lifestyle (control group) and athletes having at least one year experience were among the criteria applied.

Body weight values of the participants were measured with remiar pws 725 digital scale. Their lengths were measured with tape measure. Reaction times were measured with Newtest 1000 instrument by sitting at opposite tables in a quiet environment and the subject was positioned in such a way that the tester could not see the instrument. The best results were obtained among 5 trials. Analysis the data were used in SPSS program through One-way Anova and Independent t test and Descriptives program.

\section{Findings}

When Table 1 was examined in terms of right and left hand visual reaction time, right and left hand auditory reaction time and right and left hand mixed reaction time values, it was found that these reaction time values differed between the groups at $\mathrm{p}<0.01$ level. A striking point in this table is that the reaction time of the participants who received sports training was lower in all reaction time measurement types except the right hand auditory reaction time.

When the Table 2 is examined, the art of playing, playing any instrument, playing basketball, badminton, football, volleyball, handball, and the right and left hand visual reaction time of the sedentary, right and left hand auditory reaction time and right and left hand mixed reaction time values $\mathrm{p}<0.01$ difference was found between the groups. It is also noteworthy that in all of the reaction time types measured, the participants who received painting training had longer reaction time than the other groups.

\section{Discussion}

As the reaction time of the participants was examined on the basis of faculties, the mean visual reaction time of the right hand was $418.41 \pm 82.64 \mathrm{~ms}$ in the participants of fine arts education, $380.87 \pm 57.52 \mathrm{~ms}$ in the sports participants and $4.05 .69 \pm 60.43 \mathrm{~ms}$ in sedentary participants. When these mean values were examined, it was identified that the right hand reaction times of the participants who received sports training were lower than the sedentary and participants who received fine arts education. Through the statistical comparison of these values, it was seen that there was a significant $(\mathrm{p}<0.01)$ difference between the students who received sports education and those who received fine arts education. 
Table-1. Reaction time mean values and significance levels in sports, fine arts and primary school education.

\begin{tabular}{|c|c|c|c|c|c|c|}
\hline Variables & Groups & $\mathbf{N}$ & Average & Standard deviation & $\mathbf{F}$ & $\bar{p}$ \\
\hline \multirow{4}{*}{$\begin{array}{l}\text { Right hand visual } \\
\text { reaction time }(\mathrm{ms})\end{array}$} & $\begin{array}{l}\text { Subjects receiving fine arts } \\
\text { education }\end{array}$ & 34 & $418.41^{* *}$ & 82.64 & \multirow{4}{*}{4.304} & \multirow{4}{*}{0.01} \\
\hline & $\begin{array}{lll}\begin{array}{l}\text { Subjects } \\
\text { training }\end{array} & \text { receiving } & \text { sports } \\
\end{array}$ & 82 & $380.87 * *$ & 57.52 & & \\
\hline & Faculty of education & 16 & 405.69 & 60.43 & & \\
\hline & Total & 132 & 393.55 & 66.79 & & \\
\hline \multirow{4}{*}{$\begin{array}{l}\text { Left hand visual } \\
\text { reaction time }(\mathrm{ms})\end{array}$} & $\begin{array}{l}\text { Subjects receiving fine arts } \\
\text { education }\end{array}$ & 34 & $427.41 * *$ & 85.55 & \multirow{4}{*}{4.713} & \multirow{4}{*}{0.01} \\
\hline & $\begin{array}{lll}\begin{array}{l}\text { Subjects } \\
\text { training }\end{array} & \text { receiving } & \text { sports } \\
\end{array}$ & 82 & $385.90^{* *}$ & 66.94 & & \\
\hline & Faculty of education & 16 & 423.81 & 77.32 & & \\
\hline & Total & 132 & 401.19 & 75.41 & & \\
\hline \multirow{4}{*}{$\begin{array}{l}\text { Right hand auditory } \\
\text { reaction time }(\mathrm{ms})\end{array}$} & $\begin{array}{l}\text { Subjects receiving fine arts } \\
\text { education }\end{array}$ & 34 & $386.82^{* *}$ & 70.78 & \multirow{4}{*}{7.735} & \multirow{4}{*}{0.01} \\
\hline & $\begin{array}{|lll|}\begin{array}{l}\text { Subjects } \\
\text { training }\end{array} & \text { receiving } & \text { sports } \\
\end{array}$ & 82 & $340.83^{* *}$ & 53.37 & & \\
\hline & Faculty of education & 16 & $339.69^{* *}$ & 59.74 & & \\
\hline & Total & 132 & 352.54 & 61.96 & & \\
\hline \multirow{4}{*}{$\begin{array}{l}\text { Left hand auditory } \\
\text { reaction time }(\mathrm{ms})\end{array}$} & $\begin{array}{l}\text { Subjects receiving fine arts } \\
\text { education }\end{array}$ & 34 & $390.21^{* *}$ & 86.19 & \multirow{4}{*}{7.537} & \multirow{4}{*}{0.01} \\
\hline & $\begin{array}{lll}\begin{array}{l}\text { Subjects } \\
\text { training }\end{array} & \text { receiving } & \text { sports } \\
\end{array}$ & 82 & $338.12^{* *}$ & 54.42 & & \\
\hline & Faculty of education & 16 & $354.94 * *$ & 69.81 & & \\
\hline & Total & 132 & 353.58 & 68.98 & & \\
\hline \multirow{4}{*}{$\begin{array}{l}\text { Confused right hand } \\
\text { (Audio / Visual) } \\
\text { reaction time (ms) }\end{array}$} & $\begin{array}{l}\text { Subjects receiving fine arts } \\
\text { education }\end{array}$ & 34 & $428.18^{*}$ & 74.44 & \multirow{4}{*}{3.571} & \multirow{4}{*}{0.03} \\
\hline & $\begin{array}{lll}\begin{array}{l}\text { Subjects } \\
\text { training }\end{array} & \text { receiving } & \text { sports } \\
\end{array}$ & 82 & $396.24^{*}$ & 51.31 & & \\
\hline & Faculty of education & 16 & 416.13 & 71.62 & & \\
\hline & Total & 132 & 406.88 & 61.58 & & \\
\hline \multirow{4}{*}{$\begin{array}{l}\text { Confused left hand } \\
\text { (Audio / Visual) } \\
\text { reaction time (ms) }\end{array}$} & $\begin{array}{l}\text { Subjects receiving fine arts } \\
\text { education }\end{array}$ & 34 & $437.06^{* * *}$ & 85.47 & \multirow{4}{*}{4.101} & \multirow{4}{*}{0.01} \\
\hline & $\begin{array}{|lll|}\begin{array}{l}\text { Subjects } \\
\text { training }\end{array} & \text { receiving } & \text { sports } \\
\end{array}$ & 82 & $402.27 * *$ & 56.41 & & \\
\hline & Faculty of education & 16 & 434.38 & 65.91 & & \\
\hline & Total & 132 & 415.12 & 67.64 & & \\
\hline
\end{tabular}

When the left-hand visual reaction time averages of the participants are taken into account, $427.41 \pm 85.55 \mathrm{~ms}$ in fine arts education, $385,90 \pm 66.94 \mathrm{~ms}$ in sports participants, this average value is $423.81 \pm 77.32 \mathrm{~ms}$ in sedentary participants.

In the study, the lowest left hand visual reaction time was identified to have those who have sports training between the groups.

In the study, according to the mean right hand auditory reaction times of the participants included, $386.82 \pm$ $70.78 \mathrm{~ms}$ of the participants of fine arts education, $340.83 \pm 53.37 \mathrm{~ms}$ of the participants of sports education and $339.69 \pm 59$ of sedentary participants were found to have an average of $74 \mathrm{~ms}$.

The participants with the lowest right hand auditory reaction time were identified to be significantly lower ( $\mathrm{p}$ $<0.01)$. When the average of left hand auditory reaction time between the groups were studied, the average of the participants who received fine arts education was $390.21 \pm 86.19 \mathrm{~ms}$, the average of the people who received sports training was $338,12 \pm 54.42 \mathrm{~ms}$, while the average of sedentary participants $354.94 \pm 69$, $81 \mathrm{~ms}$. As these mean values were statistically compared, it was found that the students who received fine arts education were significantly higher $(\mathrm{p}<0.01)$ than those who had sports education and sedentaries. The average right hand mixed (visual / auditory) reaction time of the participants who received fine arts education was 428.18 $\pm 74.44 \mathrm{~ms}, 396.24$ $\pm 51.31 \mathrm{~ms}$ for sports participants and $416.13 \pm 71.62 \mathrm{~ms}$ for sedentary participants.

Despite those who having sport training was lower than the average of the two groups, it was found that there was a statistically significant difference $(p<0.01)$ in comparison with those who having fine arts education.

In addition, when the average of left hand mixed (visual / auditory) reaction time of the participants was studied in line with the groups and 437,06 $\pm 85,47 \mathrm{~ms}$ of the participants receiving fine arts education, 402,27 \pm $56,41 \mathrm{~ms}$ of the participants receiving sports training and 434,38 ms of the sedentary $\pm 65.91 \mathrm{~ms}$ were found to have an average.

it was found that sports training subjects having the shortest left hand mixed reaction time according to these averages, were statistically significantly lower $(\mathrm{p}<0.01)$ than those receiving arts education.

Ghuntla et al. (2012) compared basketball players to healthy adult control group and found that the former group had significantly shorter RZ data.

The study on the students of the Air Force Academy by Kamuk (2006) showed that simple reaction time (BRZ) was not effective in the Olympic sports branches but that the first grades provide shorter RZ in comparison with the fourth grades. 
Table-2. Distribution of right and left hand audiovisual and mixed reaction time average values by participants' branches.

\begin{tabular}{|c|c|c|c|c|c|c|}
\hline Variables & Branch & $\mathbf{N}$ & Average & Standard deviation & $\mathbf{F}$ & p \\
\hline \multirow{9}{*}{$\begin{array}{l}\text { Right hand visual } \\
\text { reaction time }(\mathrm{ms})\end{array}$} & Picture & 16 & $453,62^{*}$ & 81,31 & \multirow{9}{*}{3,219} & \multirow{9}{*}{,004 } \\
\hline & Basketball & 20 & 399,8 & 54,64 & & \\
\hline & Badminton & 11 & $356,54^{*}$ & 39,54 & & \\
\hline & Football & 18 & 385,28 & 51,5 & & \\
\hline & Volleyball & 16 & 379,87 & 55,36 & & \\
\hline & Music & 18 & 387,11 & 72,16 & & \\
\hline & Sedentary & 16 & 405,69 & 60,44 & & \\
\hline & Handball & 17 & 370,59 & 74,48 & & \\
\hline & Total & 132 & 393,54 & 66,8 & & \\
\hline \multirow{9}{*}{$\begin{array}{l}\text { Left hand visual } \\
\text { reaction time }(\mathrm{ms})\end{array}$} & Picture & 16 & $459,87^{*}$ & 81,53 & \multirow{9}{*}{2,916} & \multirow{9}{*}{,003 } \\
\hline & Basketball & 20 & 394,15 & 67,5 & & \\
\hline & Badminton & 11 & 370,54 & 77,67 & & \\
\hline & Football & 18 & $364,24 *$ & 65,4 & & \\
\hline & Volleyball & 16 & 384,87 & 60,55 & & \\
\hline & Music & 18 & 398,55 & 80,44 & & \\
\hline & Sedentary & 16 & 423,81 & 77,3 & & \\
\hline & Handball & 17 & 410,29 & 64,08 & & \\
\hline & Total & 132 & 401,19 & 75,41 & & \\
\hline \multirow{9}{*}{$\begin{array}{l}\text { Right hand auditory } \\
\text { reaction time (ms) }\end{array}$} & Picture & 16 & $408,87^{* *} *$ & 62,66 & \multirow{9}{*}{3,447} & \multirow{9}{*}{0,00} \\
\hline & Basketball & 20 & 352,5 & 48,42 & & \\
\hline & Badminton & 11 & 324,18 & 39,39 & & \\
\hline & Football & 18 & $329,11^{* *}$ & 56,47 & & \\
\hline & Volleyball & 16 & 333,87 & 39,68 & & \\
\hline & Music & 18 & 367,22 & 73,47 & & \\
\hline & Sedentary & 16 & 339,69 & 59,74 & & \\
\hline & Handball & 17 & 356,82 & 70,23 & & \\
\hline & Total & 132 & 352,54 & 61,96 & & \\
\hline \multirow{9}{*}{$\begin{array}{l}\text { Left hand auditory } \\
\text { reaction time }(\mathrm{ms})\end{array}$} & Picture & 16 & $411,12^{* *}$ & 92,47 & \multirow{9}{*}{3,776} & \multirow{9}{*}{0,00} \\
\hline & Basketball & 20 & 347,6 & 62,6 & & \\
\hline & Badminton & 11 & $311,64 * *$ & 30,02 & & \\
\hline & Football & 18 & $313,12^{* *} *$ & 35,07 & & \\
\hline & Volleyball & 16 & 346,37 & 66,38 & & \\
\hline & Music & 18 & 370,67 & 78,58 & & \\
\hline & Sedentary & 16 & 352,87 & 68,67 & & \\
\hline & Handball & 17 & 360,35 & 49,53 & & \\
\hline & Total & 132 & 352,86 & 68,97 & & \\
\hline \multirow{9}{*}{$\begin{array}{l}\text { Confused right hand } \\
\text { (Audio } \\
\text { reaction time }(\mathrm{ms})\end{array}$} & Picture & 16 & $454,5^{* *}$ & 74,13 & \multirow{9}{*}{2,581} & \multirow{9}{*}{0,01} \\
\hline & \begin{tabular}{|l|} 
Basketball \\
\end{tabular} & 20 & 397,8 & 53,55 & & \\
\hline & Badminton & 11 & $364,9 * *$ & 33,91 & & \\
\hline & Football & 18 & 389 & 59,7 & & \\
\hline & Volleyball & 16 & 408,37 & 39,71 & & \\
\hline & Music & 18 & 406,89 & 71,62 & & \\
\hline & Sedentary & 16 & 415,12 & 72,1 & & \\
\hline & Handball & 17 & 408,35 & 51,82 & & \\
\hline & Total & 132 & 406,71 & 62,09 & & \\
\hline \multirow{9}{*}{$\begin{array}{l}\text { Confused left hand } \\
\text { (Audio /Visual) } \\
\text { reaction time }(\mathrm{ms})\end{array}$} & Picture & 16 & $478,75^{* * *}$ & 80,05 & \multirow{9}{*}{3,53} & \multirow{9}{*}{0,00} \\
\hline & Basketball & 20 & 415 & 60,25 & & \\
\hline & Badminton & 11 & 379,64 *** & 48,08 & & \\
\hline & Football & 18 & 396 & 62,1 & & \\
\hline & Volleyball & 16 & 401,69 & 61,5 & & \\
\hline & Music & 18 & 398,33 & 73,04 & & \\
\hline & Sedentary & 16 & 433,25 & 64,79 & & \\
\hline & Handball & 17 & 408,18 & 45,94 & & \\
\hline & Total & 132 & 414,64 & 67,52 & & \\
\hline
\end{tabular}

This difference results from the concentration level.

The effects of physical exercise on the 11 players engaging in team sports are studied by Davranche et al. (2006) the study states that as performing physical exercise with $90 \%$ performance, both mean variance and accuracy of selective RZ results were higher than participants' results in resting state, and this might be due to central noradrenergic activation.

Nakamoto and Mori (2008) reported that university students keen on basketball and baseball had better RZ values than those who did not do sports. The study by Kaur et al. (2006) on athletes, healthy individuals and diabetics; found that athletes had better selective reaction times (RZ) than non-athletes and healthy individuals had better than diabetic patients. Speed in technical applications is a very important feature in achieving accomplishment in sports activities. In this context, coaches give importance to the application of a technique as fast as the accuracy. They plan trainings to improve this. These trainings contribute to the development of visual and auditory reactions. In fine arts, generally, slower and more careful applications give better results. It is thought 
that these training sessions may be effective in lowering the reaction time of the participants who received sports training from those who received fine arts education and sedentaries.

When the right-hand visual reaction time values of the participants included in the study are studied according to their branches, the average right-hand visual reaction time of the photographers is $453.62 \pm 81.31 \mathrm{~ms}$, the average right-hand visual reaction time of badminton players is 356.54 $\pm 39.54 \mathrm{~ms}$, the right-hand visual reaction of footballers, the mean time of the right hand visual reaction of the sedentary participants was $385.28 \pm 51.50 \mathrm{~ms}$ and $405.69 \pm 60.44 \mathrm{~ms}$. As a result of statistical comparison of these values, there was a significant difference between the groups $(\mathrm{p}<0.01)$. Olçücü et al. (2011) performed 12-week movement training to girls in the tennis branch. At the end of the study, there was a significant difference in sound and light reaction times, and the movement training applied with the ball improved the skills related to the skills such as reaction time better, they stated that it would have a positive effect on the sporting performance of children. Arslan (2014) positive visual and auditory reaction rates of exercise (Senel et al., 1997) in their study of the right hand visual reaction time of Turkish national cyclists $(0.17 \pm 0.03)$ found. The literature data support the findings of the study.

When the left-hand visual reaction time values are analyzed according to the branches of the participants, the average left-hand visual reaction time of the photographers is $459.87 \pm 81.53 \mathrm{~ms}$, the left-hand visual reaction time of badminton players is $370.54 \pm 77.67 \mathrm{~ms}$, the average left-hand visual reaction time of footballers is 364 , the mean visual reaction time of the left hand of the sedentary participants was $423.81 \pm 77.30 \mathrm{~ms}$. As a result of statistical comparison of these values, a significant difference was found between the groups $(p<0.01)$.

When the right hand auditory reaction time values of all participants were studied by branches, the average visual reaction time of the right hand of the photographers was $408.87 \pm 62.66 \mathrm{~ms}$, the average of the right auditory reaction time of badminton players was $324.18 \pm 39.39 \mathrm{~ms}$, the right hand auditory reaction time of basketball players was $352,50 \pm 48.42 \mathrm{~ms}$ and right hand auditory response time of sedentary participants was $339.69 \pm 59.74 \mathrm{~ms}$. As a result of statistical comparison of these values, there was a significant difference between the groups $(\mathrm{p}<0.01)$. Keskin (2008) found that regular physical exercises had a positive effect on auditory response time. The literature findings support the study findings.

When the left hand auditory reaction time values are studied by branches of the participants, the average of the left hand auditory reaction time of the photographers is 411,12 $\pm 92,47 \mathrm{~ms}$, the average of the left hand auditory reaction time of badminton players is $311,64 \pm 30,02 \mathrm{~ms}$, the average of the left hand auditory reaction time of volleyball players is 346 . The mean time of left hand auditory reaction of sedentary participants was $352.87 \pm 68.67$ $\mathrm{ms}$, whereas it was found that there was a significant $(\mathrm{p}<0.01)$ difference between the groups. Polat (2009) stated that badminton training program is important for improving the motoric functions of children aged 9-12 and in terms of improving their reaction time. The findings of the study support the literature.

When the right-hand mixed (visual / auditory) reaction time values of all subjects are considered by branches of the participants, the average right-hand mixed (visual / auditory) reaction time of the photographers is $454,50 \pm$ $74,13 \mathrm{~ms}$, the right-hand mixed (visual / auditory) reaction time of the badminton players mean 364,90 $\pm 33,91 \mathrm{~ms}$, right handed (visual / auditory) reaction time of the players is 389,00 $\pm 59,70 \mathrm{~ms}$, while the right hand mixed (visual / auditory) reaction time of sedentary participants is $415,12 \pm 72,10 \mathrm{~ms}$. As a result of statistical comparison of these values, a significant difference was found between the groups ( $p<0.05)$. Orhan (2013) reports that despite the rope training program does not affect the visual and auditory reaction time, anaerobic properties affect heart rate. However, as in our studies and in the literature, it shows that sports and physical activities improve the reaction rates of individuals. Imamoglu and Kilicgil (2007) " the reaction time in the tiny footballers in Turkey, vital capacity values and lateralization distribution of left-handedness problem " in his research of the players on the position for technical tactics being useful in the training of the players' skills, as well as reaction time stated in the workout might develop. Çankaya et al. (2014) state that their training program improves their reaction rates in order to improve balance. Orhan (2001) the reaction time of athletes with high anaerobic power is better expressed. The result of the research supports the literature.

The left hand mixed (visual / auditory) reaction time values of the subjects were taken into account of the branches of participants. The average left hand mixed (visual / auditory) reaction time of the photographers was $478,75 \pm 80,05 \mathrm{~ms}$, the average of the left hand mixed (visual / auditory) reaction time of the badminton players $379,64 \pm 48,08 \mathrm{~ms}$, handball players left hand mixed (visual / auditory) reaction time average of $408.18 \pm 45.94 \mathrm{~ms}$ while the left hand mixed (visual / auditory) reaction time average of $433.25 \pm 64,79 \mathrm{~ms}$. As a result of statistical comparison of these values, there was a significant difference ( $\mathrm{p}<0.01)$ between the groups. Yildırım et al. (2011) 810 years old girls playing tennis sport, right-left hand visual and auditory reaction time applied to the 3-month training stated that the positive development. Trombly (2004) reported that progress can be achieved through exercise at the time of reaction. The findings of the study are in line with the literature. Although there are studies on the comparison of reaction rates between sports branches in the literature, there are limited number of studies comparing the reaction rates of individual sports and team sports. Studies on this subject can be done.

As a result, it could be said that being educated on sports is more effective on reaction time than the education of fine arts and classroom teachers included in the study. In addition, having the lowest reaction time among badminton trainees and having the highest reaction time for painting education shows the importance of these exercises beyond the dominant hand. Sevim (2002) this situation "Reaction time, as a result of regular training can be improved up to 0.12 second. This change can be achieved by maintaining the current reaction speed, by improving the technical skill level and by making the movement more economical, not by the development of the stimulus going to the brain and the speed of arriving from the brain to organs ".

\section{References}

Arslan, E., 2014. The effect of exercise program on the visual and auditory reaction times of healthy children aged 8-11 years. YYU Journal of Education Faculty, $11(1): 169-182$.

Bompa, T., 1998. Training theory and method. Ankara: Bağırgan Publishing. pp: 443.

Çankaya, S., B. Gökmen, Ç. M. and M.Y. Taşmektepligil, 2014. Effects of balance enhancing special training practices on reaction time and body mass index of 11 years old young men. Journal of Sport and Performance Research, 5(2): 59-67.

Çolakoğlu, M., S. Tiryaki and S. Moralı, 1993. Effect of concentration studies on reaction time. Journal of Sport Sciences, 4(4): $32-45$. 
Davranche, K., M. Audiffren and A. Denjean, 2006. A distributional analysis of the effect of physical exercise on a choice reaction time task. Journal of Sports Sciences, 24(3): 323-329.Available at: https://doi.org/10.1080/02640410500132165.

Fox, E.L., R.W. Bowers and M.L. Foss, 1999. Physiological foundations of physical education and sports. Translation Cerit. M., Ankara: Bağırgan Publications. pp: 346-363.

Ghuntla, T., H. Mehta, P. Gokhale and C. Shah, 2012. A comparative study of visual reaction time in basketball players and healthy controls. National Journal of Integrated Research in Medicine, 3(1): 49-51.

Imamoglu, O. and E. Kilicgil, 2007. Reaction time in little talent in Turkey, vital capacity values and the problem of distribution of lefthandedness lateralization. SPORMETRE Journal of Physical Education and Sports Sciences, 5(3): 95-100.Available at: https://doi.org/10.1501/sporm_0000000084.

Kamuk, Y.U., 2006. Combat pilot candidates studying at the air force academy simple reaction. Measurement and Evaluation of Selective Reaction and Differential Reaction Times Method Study, Master Thesis, Marmara University Institute of Educational Sciences, Istanbul.

Kaur, P., M. Paul and J.S. Sandhu, 2006. Auditory and visual reaction time in athletes, healthy controls, and patients of type 1 diabetes mellitus: A comparative study. International Journal of Diabetes in Developing Countries, 26(3): 112-115.Available at: https://doi.org/10.4103/0973-3930.32170.

Keskin, S., 2008. Comparison of auditory and simple reaction times of visually impaired individuals between 18-30 years of age and staff of the general directorate of youth and sports between 18-30 years of age. Gazi University Institute of Health Sciences: Master's Thesis.

Nakamoto, H. and S. Mori, 2008. Sport-specific decision-making in a Go/NoGo reaction task: Difference among nonathletes and baseball and basketball players. Perceptual and Motor Skills, 106(1): 163-170.Available at: https://doi.org/10.2466/pms.106.1.163-170.

Olçücü, B., A. Cenikli, M. Kaldırımcı and Ö. Bostancı, 2011. The effects of movement training with and without ball on physical fitness of tennis playing children. Journal of Sport and Performance Research, 2(1): 32-40.

Orhan, S., 2001. Comparison of reaction time, vertical jump and anaerobic power values of active athletes and sedentary students. Gazi University, Institute of Health Sciences: Master's Thesis.

Orhan, S., 2013. The effects of rope training on heart rate, anaerobic power and reaction time of the basketball players. Life Science Journal, $10(4 \mathrm{~s}): 266-271$.

Polat, G., 2009. The effects of 12-week basic badminton training exercises on motor functions and reaction times in children aged 9-12 years. Cukurova University Institute of Health Sciences: Master's Thesis.

Schmidt, E., W.J. Loesche, B.A. Smith, E.C. Morrison, R. Caffesse and P.P. Hujoel, 1991. Effects of metronidazole on periodontal treatment needs. Journal of Periodontology, 62(4): 247-257.Available at: https://doi.org/10.1902/jop.1991.62.4.247.

Senel, O., N.A. Atalay and F. Colakoglu, 1997. Physical and physiological profiles of Turkish national cyclists. Journal of Sport Sciences, 8(1): 43-49.

Sevim, Y., 1997. Training knowledge. Ankara: Nobel Publication Distribution.

Sevim, Y., 2002. Training information, 1st Edition, Ankara: Nobel Publication Distribution. pp: 78-79.

Trombly, C.A., 2004. Trombly, CA'n Randomski, M.V. Occupational therapy for physical dysfunction. 4th Edn., Williams and Wilkins.

Yıldırım, I., Ş. Karagöz and O. Y., 2011. The effects of 12 weeks of tennis training on visual and auditory reaction time in 8-10 year old girls University of Nigde. Journal of Physical Education and Sport Sciences, 5(3): 257-265. 